\title{
EMISSION FEATURES OF SEVERAL BE STARS \\ AS RELATED TO THEIR LUMINOSITY CLASS AND \\ SPECTRAL TYPE
}

H. HUBERT and M. Th. CHAMBON

Observatoire de Meudon, France

\section{Introduction}

At the Haute Provence Observatory, a survey of the Be stars brighter than the seventh magnitude was initiated by Herman and her collaborators twenty years ago.

With this material, the relationship of emission features of Be stars to their luminosity class and spectral type is investigated. At the present time, about fifty B2 and B8-9 emission stars have been studied. The plates were taken at the 1.20 meter telescope with dispersion $77 \AA \mathrm{mm}^{-1}$ at $\mathrm{H} \gamma, 120 \AA \mathrm{mm}^{-1}$ at $\mathrm{H} \beta$ and $300 \AA \mathrm{mm}^{-1}$ at $\mathrm{H} \alpha$. All these Be stars have been classified by Herman-Rojas (1973-1974). Their classification is based on the hydrogen lines. Our study of the B3 emission stars was published this year (Delplace and Hubert, 1975) and the results will only be summarized. For the B8-9 emission stars the results will be given in detail.

\section{The B2 Emission Stars}

About twenty five B2 emission line stars were studied. Using the Herman-Rojas (1974) and Rountree-Lesh (1968) classifications, we have been able to distinguish three groups of stars:

(1) First group; two sub-groups are found:

(a) the stars exhibit strong emission of the higher Balmer lines - Metallic emission lines are present.

The emission is observed to be fairly stable.

The time scale of the emission features is long: about 30 or 40 years.

(b) the stars exhibit strong emission in the higher Balmer lines, but metallic emission lines are faint or missing. The emission features are not as stable; a hydrogen shell is often present which is enhanced during the minimum of the emission.

The time scale of the emission variations is longer than or equal to 16 years.

In the first group, the stars would generally have luminosity class V or V-IV.

(2) In the second group, the stars exhibit emission only in the first Balmer lines. The emission features are not as stable. In these stars the emission lines disappear and then reappear, giving: $\mathrm{Be} \rightarrow \mathrm{B} \rightarrow \mathrm{Be}$.

The time scale of the emission variation is about 12 years.

In the Herman-Rojas and Rountree-Lesh classifications these stars would generally have luminosity class IV-III. 
(3) The third group includes the typical shell stars; they would have luminosity class III.

\section{B8-B9 Emission Stars}

Twenty-three B8-B9 emission stars were studied. As for the B2 stars, a relation between the emission features and the luminosity class is investigated.

Four stellar groups are found.

(1) In the first group the stars exhibit rather strong emission at $\mathrm{H} \alpha . \mathrm{H} \alpha$ is always in emission and $\mathrm{H} \beta$ also. The emission variations would be very faint and large. On our plates they are chiefly visible at $\mathbf{H} \beta$. Though these stars have been observed for thirty to fifty years, no time scale of the emission variation can yet be given.

During the maximum of the emission, some Fe II emission lines in the long wavelength range are observed. A faint hydrogen shell is also present before and during the maximum of the emission and some enhancements of the $\mathrm{Mg}$ II and $\mathrm{He}$ I lines are also possible.

All these stars have homogeneous emission features. In the Herman-Rojas classification, they would generally have luminosity class V (Table I).

TABLE I

Group 1 of B8-9 emission stars

\begin{tabular}{lllll}
\hline Star & $\begin{array}{l}\text { Herman- } \\
\text { Rojas } \\
\text { classifi- } \\
\text { cation }\end{array}$ & $\begin{array}{l}\text { Morguleff } \\
\text { classifi- } \\
\text { cation }\end{array}$ & $\begin{array}{l}\text { Miczaika } \\
\text { classifi- } \\
\text { cation }\end{array}$ & $\begin{array}{l}\text { Rotational } \\
\text { velocity } \\
\text { (Slettebak) }\end{array}$ \\
\hline HD 6343 & B8 IV-V & - & - & - \\
HD 9709 & B8 V & - & - & 350 \\
HD 18552 & B8 V & B9 V & - & 320 \\
HD 21641 & B9 V & - & B8 V & 160 \\
HD 23552 & B8 IV & - & - & 250 \\
HD 47054 & - & - & - & 270 \\
HD 53416 & B9 V & - & - & - \\
HD 192044 & B8 V & B8 V & - & 350 \\
HD 196712 & B7-8 V & - & - & 250 \\
HD 207232 & B8 IV ? & - & 330 \\
\hline
\end{tabular}

(2) In the second group the emission features are not stable. The emission in these stars disappears and reappears (giving $\mathrm{Be} \rightarrow \mathrm{B} \rightarrow \mathrm{Be}$ ) but when the emission is present, $\mathrm{H} \alpha$ is strong (Hubert, 1971, 1973).

The time scale of the emission variations is longer than forty-five years. During the transition phase $(\mathrm{B} \rightarrow \mathrm{Be}), \mathrm{Na}_{\mathrm{I}}, \mathrm{Ca}$ II, and $\mathrm{Mg}$ II lines are enhanced.

In the Herman-Rojas classification these stars would have luminosity class V-IV or IV (Table II). We recall the case of Pleione (B7IV), for which the time scale of the emission variations is about 60 years (Delplace and Hubert, 1973). 
TABLE II

Group 2 of B8-9 emission stars

\begin{tabular}{lllll}
\hline Star & $\begin{array}{l}\text { Herman- } \\
\text { Rojas } \\
\text { classifi- } \\
\text { cation }\end{array}$ & $\begin{array}{l}\text { Morguleff } \\
\text { classifi- } \\
\text { cation }\end{array}$ & $\begin{array}{l}\text { Miczaika } \\
\text { classifi- } \\
\text { cation }\end{array}$ & $\begin{array}{l}\text { Rotational } \\
\text { velocity } \\
\text { (Slettebak) }\end{array}$ \\
\hline HD 164447 & B8 IV & B7 IV & - & 250 \\
HD 142926 & B8 IV-V & - & B8 V & 350 \\
HD 210129 & B8 IV & - & B8 V & 200 \\
HD 216057 & B8 IV-V & B8 & - & 370 \\
\hline
\end{tabular}

(3) In the third group the stars exhibit very faint emission on a strong absorption at $\mathrm{H} \alpha$. Unhappily these stars have not been observed for a long time and, on our plates, the dispersion is not sufficient to give a time scale of the emission variations. These variations are very faint, but perhaps shorter than for the first group.

In the Herman-Rojas classification these stars would generally have luminosity class IV-III (Table III).

TABLE III

Group 3 of B8-9 emission stars

\begin{tabular}{lllll}
\hline Star & $\begin{array}{l}\text { Herman- } \\
\text { Rojas } \\
\text { classifi- } \\
\text { cation }\end{array}$ & $\begin{array}{l}\text { Morguleff } \\
\text { classifi- } \\
\text { cation }\end{array}$ & $\begin{array}{l}\text { Miczaika } \\
\text { classifi- } \\
\text { cation }\end{array}$ & $\begin{array}{l}\text { Rotational } \\
\text { velocity } \\
\text { (Slettebak) }\end{array}$ \\
\hline HD 6811 & B9 III & B8 III & B8 III & 70 \\
HD 175511 & B9 V? & - & - & - \\
HD 175869 & B8 IV-III & - & - & - \\
HD 195554 & B9 IV & - & - & 250 \\
HD 205551 & B9 III & - & - & 200 \\
\hline
\end{tabular}

(4) In the fourth group the stars exhibit a faint emission at $\mathrm{H} \alpha$ (sometimes also at $\mathrm{H} \beta$ ) or an absorption.

The time scales are certainly very large, because the absorption phase is about 40 years.

In the Herman-Rojas classification these stars would generally have luminosity class III (Table IV).

TABLE IV

Group 4 of B8-9 emission stars

\begin{tabular}{|c|c|c|c|c|c|}
\hline Star & $\begin{array}{l}\text { Herman- } \\
\text { Rojas } \\
\text { classifi- } \\
\text { cation }\end{array}$ & $\begin{array}{l}\text { Morguleff } \\
\text { classifi- } \\
\text { cation }\end{array}$ & $\begin{array}{l}\text { Miczaika } \\
\text { classifi- } \\
\text { cation }\end{array}$ & $\begin{array}{l}\text { Rountree- } \\
\text { Lesh } \\
\text { classifi- } \\
\text { cation }\end{array}$ & $\begin{array}{l}\text { Rotational } \\
\text { velocity } \\
\text { (Slettebak) }\end{array}$ \\
\hline HD 144 & B9 III-II & B8 III & B8 III & - & 170 \\
\hline HD 23302 & B8, 5 IV-III & B7-8 III & B6 III & B6 III & 230 \\
\hline HD 23630 & B8 III & B8 III & B7 III & B7 III & 210 \\
\hline HD 23850 & B8 IV-III & B8 III & - & - & - \\
\hline HD 24479 & A1 III & - & B9 III & - & 110 \\
\hline
\end{tabular}




\section{Conclusions}

(1) For a given luminosity class, the emission features are much more important for B2 than B9 stars.

(2) When the stars are going through the phases $\mathrm{Be} \rightarrow \mathrm{B} \rightarrow \mathrm{Be}$, the time scale of the emission variations is longer for B9 stars than B2.

(3) Emission features probably vary with luminosity class.

(4) The Be phenomenon is present

(a) when the B stars are leaving the main sequence

(b) when the B stars are at the end of the post main sequence contraction.

\section{References}

Delplace, A. M. and Hubert, H.: 1973, Compt. Rend. Acad. Sci. Paris 277, 575.

Delplace, A. M. and Hubert, H.: 1975, Astron. Astrophys. 38, 75.

Herman, R.: 1973, in Ch. Fehrenbach and B. E. Westerlund (eds.): 'Spectral Classification and Multicolour Photometry', IAU Symp. 50, p. 17.

Herman, R.: 1974, private communication.

Hubert, H.: 1971, Astron. Astrophys. 11, 100.

Hubert, H.: 1973, Astron. Astrophys. Suppl. 9, 133.

Rountree-Lesh, J.: 1968, Astrophys. J. Suppl. 16, 371. 